\title{
Experimental Research Work to Optimize Process Parameters into Electro Chemical Abrasive Flow Machining using Taguchi Methodology
}

\author{
Sandeep Singh \\ Research Scholar, SGI Samalkha
}

\author{
Sunil Kumar \\ Assistant Professor, SGI Samalkha
}

\begin{abstract}
Electrochemical assisted abrasive flow finishing is a newly developed hybrid finishing process which is used to finish the internal parts of work piece having complicated geometry to large extent. In electrochemical assisted abrasive flow machining higher abrasion of the material was detected due to the combine effect of ECM and AFF processes. In Electrochemical aided abrasive flow machining a electrolyte is added to the prepared media .This media consist a kind of polymeric carrier and abrasive particles that are hydrocarbon gel, Al2O3, Silicon based polymer, and NaI (Sodium iodide) as electrolytic salt. In this experimental research different process parameters such as voltage, abrasive concentration, Number of cycle, molal concentration and diameter of rod were considered at different levels for response characteristic of surface roughness (Ra) and material removal (MR) based on Taguchi method using standard L27 orthogonal array (OA) for the plan of experimentation. To determine the contribution of each parameter analysis of variance was used.
\end{abstract}

Keyword: Electrochemical machining (ECM,), Abrasive flow finishing (AFF), Taguchi Technique L27, ANOVA

\section{INTRODUCTION}

AFM is a Nontraditional type finishing process was first establish in 1970 by the Extrude Hone Corporation. These process are used to removal of recast layer, polish of critical components, radius surface debar in aeronautical, automotive, medical, electronics and die-making industries. In this process, an abrasive media passes across the work piece surface with high forces that surface to be machined. When the media is passes across the work piece through high force that time the Abrasion occur. Internal and external parts can be finished with accurate dimensions and good surface finish. AFM machining also used for inaccessible areas and complex shape of work piece. The work piece is clamped between two vertically opposed hydraulic cylinders.

The AFM process in lower hydraulic cylinder filled the proper volume of the abrasive media. The upper cylinder forces the media into the work piece. The media passed into the hollow work piece when high force applied on the upper hydraulic cylinder one cycle complete when the upper media cylinder go down completely after that come in original shape. The combination of one upstroke and one constitutes a complete AFM cycle. The key components of AFM process are machine, abrasive media and work piece. AFM parameters that is extrusion pressure, abrasive construction, number of cycles media flow rate, abrasive size, abrasive media volume and type and fixture designs and work-piece material. AFM performance measures, surface finish and material removal rate. Media carrier consists of a silicone base polymer which is supplied with a gel consisting of a hydrocarbon oil and polymers. The liquid properties of the polymer allow it to flow around and through the metal object, the details of the cast metal and conforming to the size and shape of the passages. The most frequently used abrasives are silicon carbide, aluminum oxide, boron carbide and cubic boron nitride (CBN) as well as diamond. A one-way or twoway flow of an abrasive media is used for finishing and smoothing rough surfaces. One-way abrasive flow machining media pass into the work piece and 
exits from the second end called open end. Large amount of media is require for the one way abrasive flow machining. In two-way abrasive flow machining, two opposite vertically cylinders in which abrasive media back and forth flow. The two-way type process most important for best surface finishing or edge of external, internal and otherwise deep holes, corner and slots. It is most efficient and accurate, and can be used in one-way or two-way application. The machining operation of parts emphasizes for final finish machining operations is the $15 \%$ of the total manufacturing costs. AFM setup as shows in figure 1

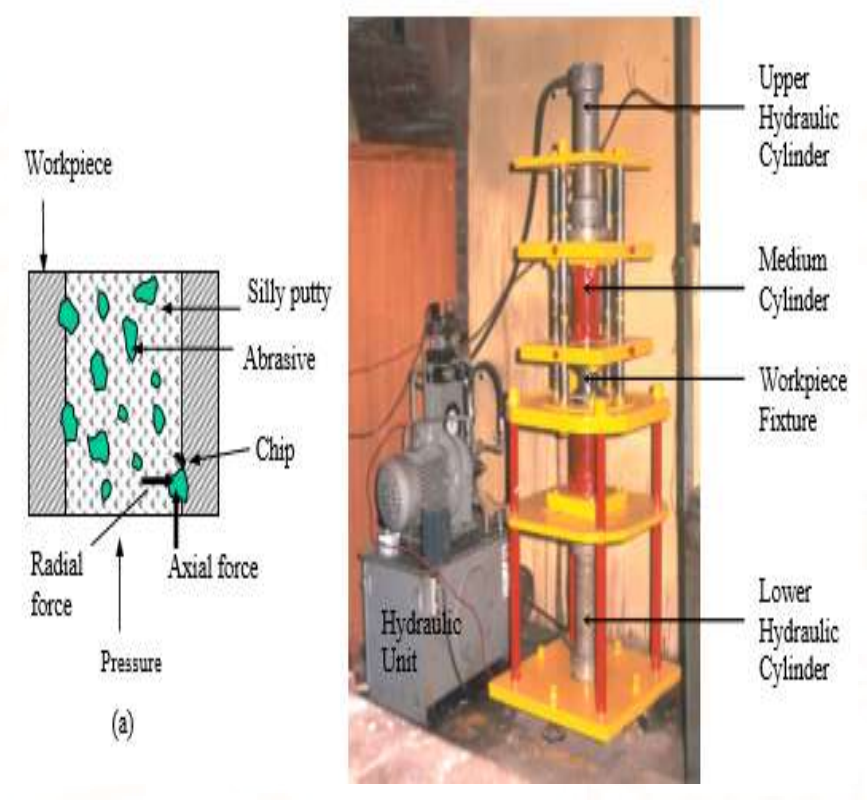

Fig 1 Abrasive Flow Machine

Now days, AFM the important processes for finish the surface of work piece which is very difficult to other machining process for accurate rage of metallic material. The surface finish produce by AFM in the range of $0.05 \mu \mathrm{m}$. the corner radius range 0.025 to $1.50 \mathrm{~mm}$ and the small holes range $0.2 \mathrm{~mm}$ successfully finish by abrasive flow machine. It has been applied in the aerospace, automotive, electronics and die-making industries.

\section{HYBRID AFM}

The nylon fixture used in ECA2FM is provided with two copper electrode in which one acts as cathode connected with triangular rod, while the other acts as anode connected with work piece. The triangular cathode rod passes between the hollow work pieces to complete the circuit of electro chemical machining. The fixture was fixed between the two opposite hydraulic cylinder tightly with screws in order to the avoid leakage. The electrodes was connected to low voltage power source having range of $0-30 \mathrm{~V}$.The media is filled in the lower cylinder and the extrusion pressure on upper cylinder is applied which allows the media to pass through the restricted space between the cathode rod and the anodic work piece. When the media flows through the space between the cathode rod and the work piece, it results in material removal rate and efficiency is increased due to the additional electrolytic machining along mechanical machining due to acting action of the abrasive. Media used for ECA2FM consists of A1203 particle, silicon based polymer and hydrogen gel with Nacl salt. The abrasive to media ratio was taken as $1: 1: 1$. The concentration of sodium chloride was varied at different level. In simple AFM process, only abrasive helps to remove material from work piece which results in less material removal. But in ECA2FM, material removal occurs by combination of AFM and ECM. It enhance the rate of material removal. When voltage applied, material was removed from workpiece due to action of ECM and abrasion action of AFM.The key parameters were voltage, no. of cycle, molal concentration and diameter of rod. Experiments were performed with simple AFM process and by making it hybrid as ECA2FM. The schematic diagram is shown in figure 2 . 


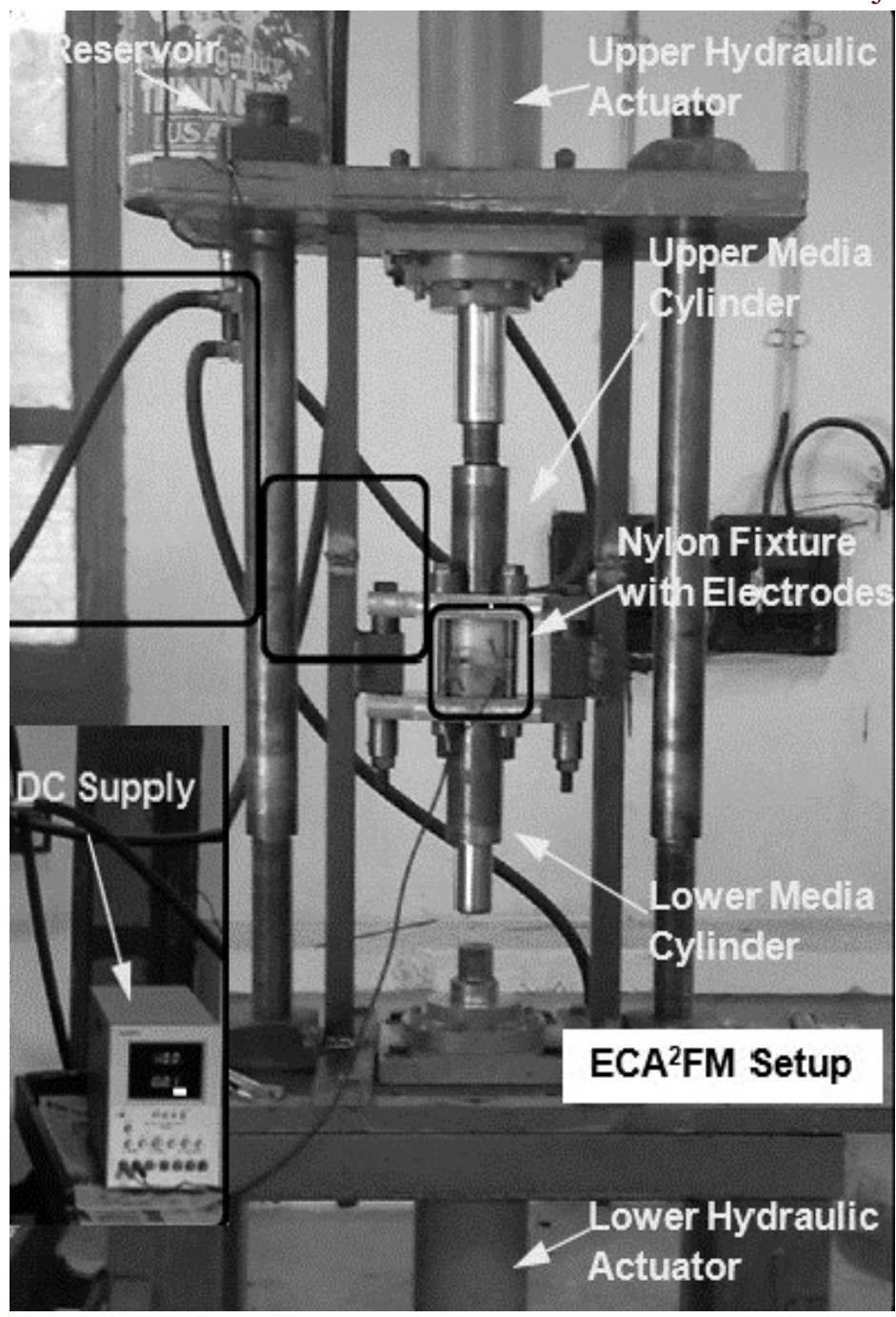

Fig 2. ECA ${ }^{2}$ FM Set Up

The gun metal was used as work-piece material in experiments. The workpiece was given hollow cylindrical shape by drilling process followed by boring. The dimension was taken as $8 \mathrm{~mm}$ internal diameter, $12.6 \mathrm{~mm}$ external diameter and $15 \mathrm{~mm}$ length as shown in figure 3 .

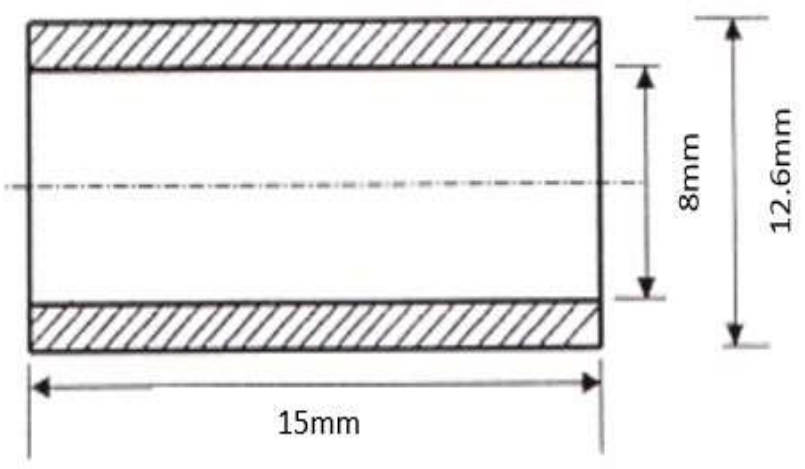

Figure 3: Work-Piece

\section{Literature Survey}

Many researchers presented their own theories on the abrasive flow machining such as Rhoades [1-3] study the basic principle of AFM process and identified its control parameters. He observed that its viscosity temporarily rise when the medium is suddenly forced through restrictive passage. AFM can be used in industrial applications such as automobile, medical, aerospace etc. [4]. Rajurkar [5] studied the effect of medium viscosity and extrusion pressure on metal removal rate and surface finish used the full factorial design for experimentation. Jain and Adsul [6] reported that initial surface roughness and hardness of the work piece are important parameters affecting the material removal rate in AFM. Loveless [7] studied on surface finish the effect of viscosity of media. They found that viscosity is the only parameter which significantly affects the surface finish. They found the relationship between initial surface finish and percentage improvement in surface finish is nonlinear. Singh and Shan [8] applied a magnetic field around the work piece and observed that the presence of magnetic field significantly improves the surface finish and material removal. This improvement is mainly due to the increased concentration of abrasive at the work piece and medium. The objective of the present paper is to analysis the effect of extrusion pressure, grain size, abrasive concentration on material removal and surface finish. Electro chemical aided abrasive flow machining was possible with the help of polymeric electrolytes Dabrowski et al. 2006 [9].B.S. Brar [10] experimented with the abrasive flow machining combined with simple ECM process i.e. ECA2FM. The shape of drill bit (helical) also affects the quality of surface. Walia study the impact of central force on the abrasive flow machining process through experiments, told the relation of shaft speed, cycle index, and the grain size to improve the surface roughness and material removal amount [1112]. Agrawal et al. [8] Used poly boro siloxane as media and predicted the viscoelastic properties of media such as viscosity, creep compliance and bulk modulus. Przylenk described that with small bore diameter of work piece, more grains comes in contact with the surface, hence improves surface finish [14]. This process can be applied to finish the component up to nano level surface roughness [15] 


\section{Experimentation-Work}

The change in material removal value is calculated as:

\section{Change in $\mathrm{MR}=$ Initial weight - Final weight (mg)}

The surface roughness ( $\mathrm{Ra}$ ) was depicted by Mitutoyo SJ-201surface roughness testing machine. For design, L9 (3) orthogonal array based on taguchi based methodology was used. All process parameter has been studied at three levels. To measure the effect of each parameter, analysis of variance was performed for both $\mathrm{S} / \mathrm{N}$ and Raw data. The material removal is higher the better type quality characteristics, so signal to noise $(\mathrm{S} / \mathrm{N})$ ratio was calculated for this type as:

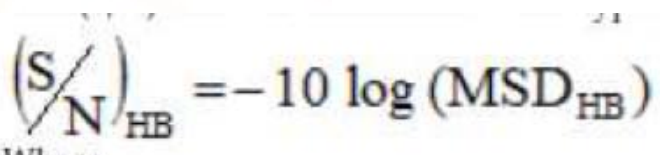 \\ Where}

$$
\operatorname{MSD}_{\mathrm{HB}}=\frac{1}{R} \sum_{j=1}^{R}\left(1 / y_{j}^{2}\right)
$$

MSD represents mean square deviation, which present: Effect of voltage on S/N data \& RAW data.

the average squares of all deviations from the target value rather than around the average value.

$\mathrm{R}=$ Number of repetitions, $\mathrm{y}=$ response value

Table 1. Constant Process Parameter and their Value

\begin{tabular}{|c|c|c|c|}
\hline $\begin{array}{l}\text { Sr. } \\
\text { No. }\end{array}$ & Process Parameters & Range & Unit \\
\hline 1 & Shape of CFG rod & Triangular & $-\cdots$ \\
\hline 2 & Diameter of CFG rod & 4.2 & $\mathrm{~mm}$ \\
\hline 3 & Initial surface $\mathrm{Ra}$ & -------- & $\mu \mathrm{m}$ \\
\hline 4 & Media flow volume & 290 & $\mathrm{~cm}^{3}$ \\
\hline 5 & Fixture material & Nylon & ------ \\
\hline 6 & Polymer-Gel ratio & $1: 1$ & percentage \\
\hline 7 & Temperature & $30 \pm 2$ & $\begin{array}{l}\text { by weight } \\
{ }^{\circ} \mathrm{C}\end{array}$ \\
\hline 8 & Reduction Ratio & 0.94 & ---- \\
\hline
\end{tabular}

Table 2 Process parameters value at different level

\begin{tabular}{|c|c|c|c|c|c|}
\hline Parameter & Unit & Sym & Level1 & Level2 & Level3 \\
\hline Voltage & Volt & $\mathrm{V}$ & 0 & 15 & 25 \\
\hline Molal Conc. & No.(micron) & $\mathrm{M}$ & 0.75 & 1.00 & 1.25 \\
\hline $\begin{array}{c}\text { Abrasive } \\
\text { concentration }\end{array}$ & $\ldots \ldots \ldots \ldots$ & $\mathrm{C}$ & 0.8 & 1 & 1.2 \\
\hline $\begin{array}{c}\text { No. of cycle } \\
\text { N.......... }\end{array}$ & $\mathrm{N}$ & 8 & 10 & 12 \\
\hline Dia of rod & $\mathrm{mm}$ & $\mathrm{D}$ & 3.2 & 4.2 & 5.2 \\
\hline
\end{tabular}

\section{Results}

Experimental design was prepared using L27 orthogonal array based upon taguchi technique. Total 81 experiments were performed. The Material removal for $\mathrm{S} / \mathrm{N}$ ratio $\&$ average value of raw data at three levels L1, L2, L3 for each parameter shown in table. (a)

Table 3 Main Effect (S/N \& Raw data)

\begin{tabular}{|l|l|l|l|l|l|l|l|}
\hline $\begin{array}{l}\text { S } \\
\text { N }\end{array}$ & $\begin{array}{l}\text { Process } \\
\text { Parameter }\end{array}$ & \multicolumn{2}{|l|}{ Level 1 } & \multicolumn{2}{l|}{ Level 2 } & \multicolumn{2}{l|}{ Level 3 } \\
\hline & & $\begin{array}{l}\text { Raw } \\
\text { Data }\end{array}$ & $\begin{array}{l}\text { S/N } \\
\text { Data }\end{array}$ & $\begin{array}{l}\text { Raw } \\
\text { Data }\end{array}$ & $\begin{array}{l}\text { S/N } \\
\text { Data }\end{array}$ & $\begin{array}{l}\text { Raw } \\
\text { Data }\end{array}$ & $\begin{array}{l}\text { S/N } \\
\text { Data }\end{array}$ \\
\hline 1 & Voltage (V) & 10.45 & 18.48 & 12.73 & 21.32 & 13.85 & 21.71 \\
\hline 2 & $\begin{array}{l}\text { Salt Molal } \\
\text { concentration }\end{array}$ & 10.69 & 17.94 & 12.24 & 21.06 & 14.10 & 22.51 \\
\hline 3 & $\begin{array}{l}\text { Abrasive } \\
\text { Concentration }\end{array}$ & 10.44 & 18.12 & 12.76 & 21.08 & 13.83 & 22.30 \\
\hline 4 & $\begin{array}{l}\text { No. of cycle } \\
\text { (N) }\end{array}$ & 11.40 & 18.93 & 12.78 & 20.91 & 12.85 & 21.67 \\
\hline 5 & \begin{tabular}{l} 
Dia of Rod(D) \\
\hline
\end{tabular} & 11.84 & 19.57 & 11.76 & 20.06 & 13.43 & 21.89 \\
\hline
\end{tabular}




\section{Graph Discussion}

\section{Voltage}

From this graph (a) as shows in it can be noticed that as voltage is applied material removal increase. This is due to fact of without voltage material removal occurs due to only simple AFM. But when voltage is applied material removal occurs by the contribution of ECM and AFM hence the rate of MR.

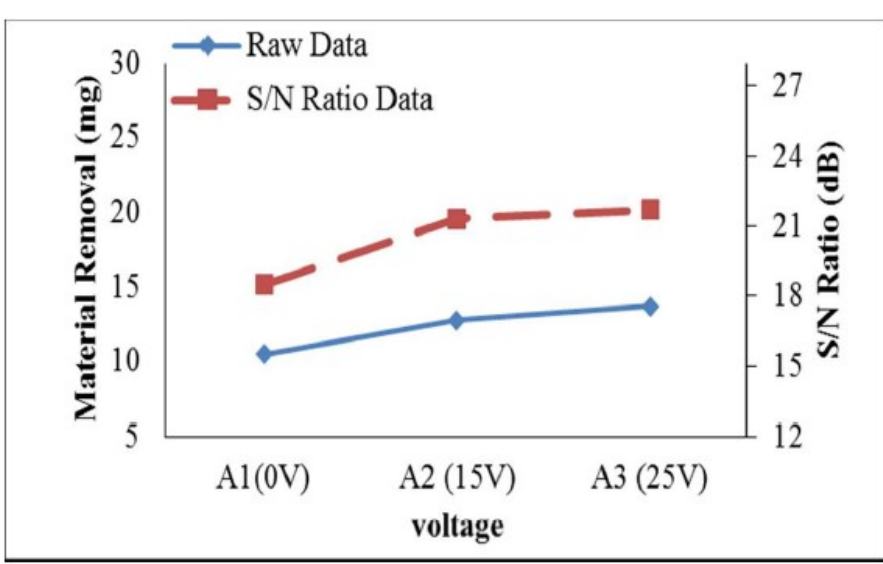

(a) Effect of voltage on $\mathrm{S} / \mathrm{N}$ data $\&$ RAW data

\section{Molal Concentration}

As molal concentration increase the viscosity of media decrease but material removal increase. This happens because of molal concentration increase the rate of give high material removal. If the number of cycle electrochemical machining and hence the material increase 8 to 10 the material removal also increase. removal. The effect of Molal concentration show in Graph (b)

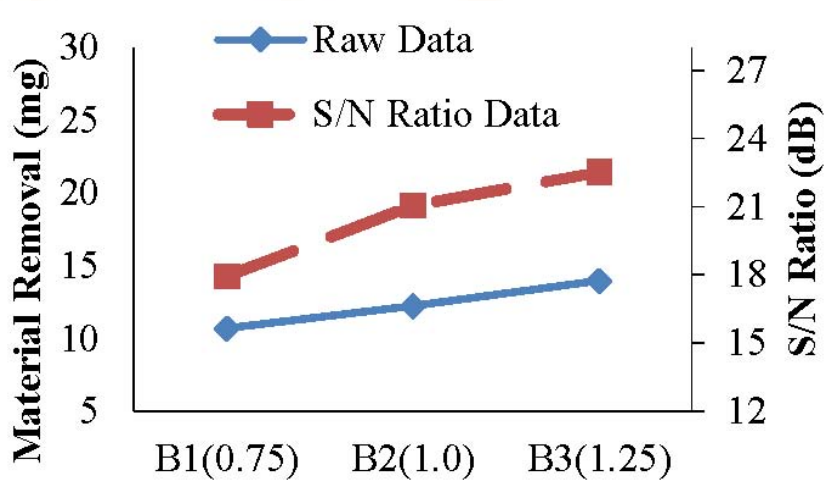

Molal Concentration (mole/kg)

\section{Abrasive concentration:}

From graph (c) is was concluded that as the concentration of abrasive increases the material removal is also increases. At higher concentration, more abrasive particle comes in contact with work piece resulting in more abrasion, which improves material.

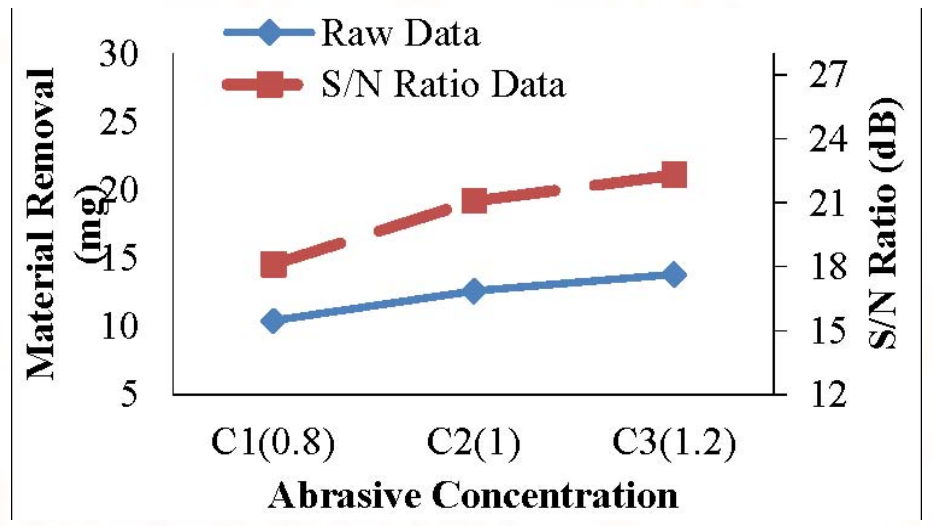

\section{(c) Effect of Abrasive Concentration on $\mathrm{S} / \mathrm{N}$ data $\&$} RAW data

\section{Number of Cycle}

From this graph (d) it was noted that number of cycle have a major effect on finishing quality of work piece. In starting, material was removed from edges, which give high material removal. If the number of cycle increase 8 to 10 the material removal also increase.

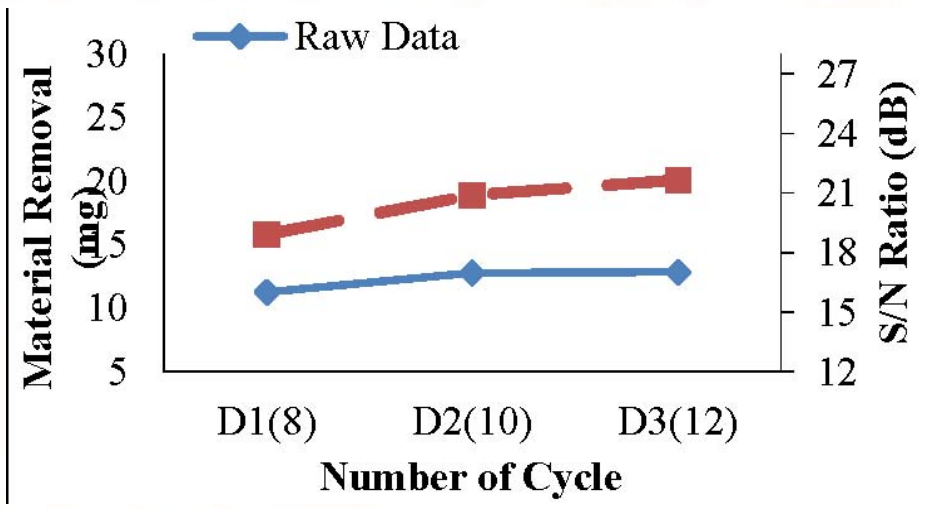

(d) Effect of Number of Cycle on $\mathrm{S} / \mathrm{N}$ data \& RAW data

(b) Effect of Molal Concentration on $\mathrm{S} / \mathrm{N}$ data $\&$ RAW data 


\section{Diameter of Rod}

From this graph (e) it can be calculated that as the diameter of cathode tool inside the work-piece increase it decrease the gap between the tool and work-piece which increase the rate of abrasive flow machining and electrochemical machining and hence material removal

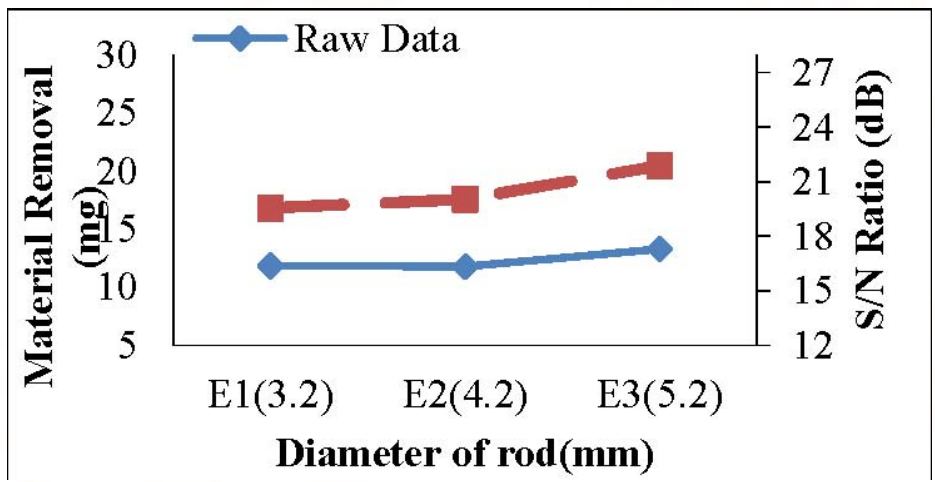

(e) Effect of Diameter of $\operatorname{Rod}$ on $\mathrm{S} / \mathrm{N}$ data \& RAW data

\section{Interaction Graphs}

The ECA FM process is very interactive. The effects of three two-factor interactions, i.e. voltage and salt molal concentration $(\mathrm{VxM})$, voltage and abrasive concentration $(\mathrm{VxC})$ and voltage and no. of cycle $(\mathrm{VxN})$, on the response parameter material removal(MR) are plotted by calculating average values of response characteristics for respective twofactor interaction at different level combinations.

It is observed that the two-factor interaction of voltage and salt molal concentration (VxM), voltage and abrasive concentration $(\mathrm{V} \times \mathrm{C})$ and voltage and number of cycle $(\mathrm{V} \times \mathrm{N})$ is significant based on ANOVA (raw data) and is insignificant based on ANOVA $\mathrm{S} / \mathrm{N}$ ratio data. Based on the raw data analysis too, it is the least significant parameter affecting the MR. The little observed effect of this interaction is explained by the fact that salt molal concentration (M), abrasive concentration and number of cycle has a role to play in the MR only in the presence of some applied voltage (V). All interaction as shows in graph $\mathrm{f}$, $\mathrm{g}$ and $\mathrm{h}$ respectively.

\section{(f).Voltage and Molal Concentration $(\mathrm{V} \times \mathrm{M})$}

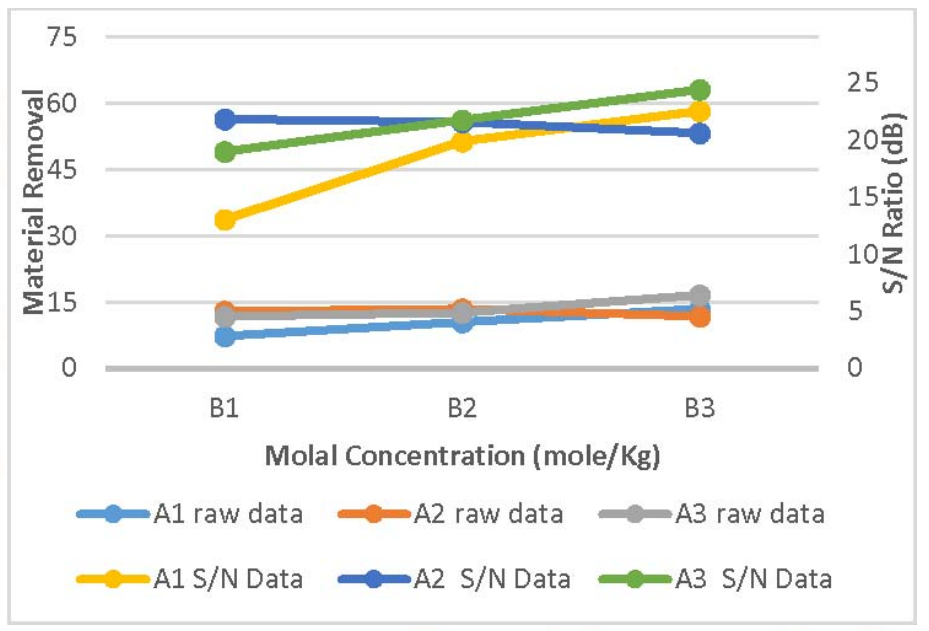

(g)Voltage and Number of Cycle $(\mathrm{V} \times \mathbf{N})$

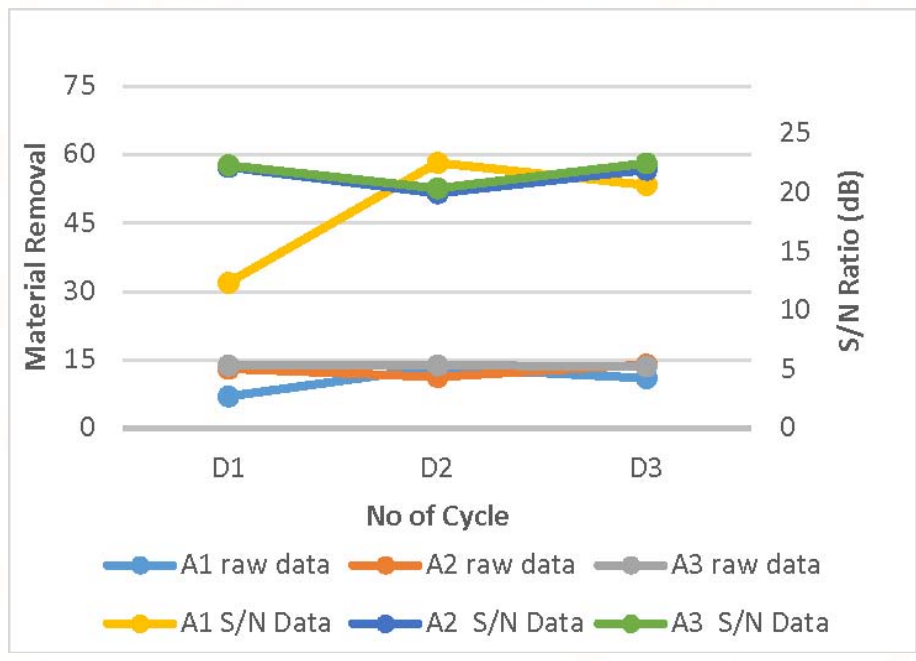

(g)Voltage and Number of Cycle $(\mathrm{V} \times \mathrm{N})$

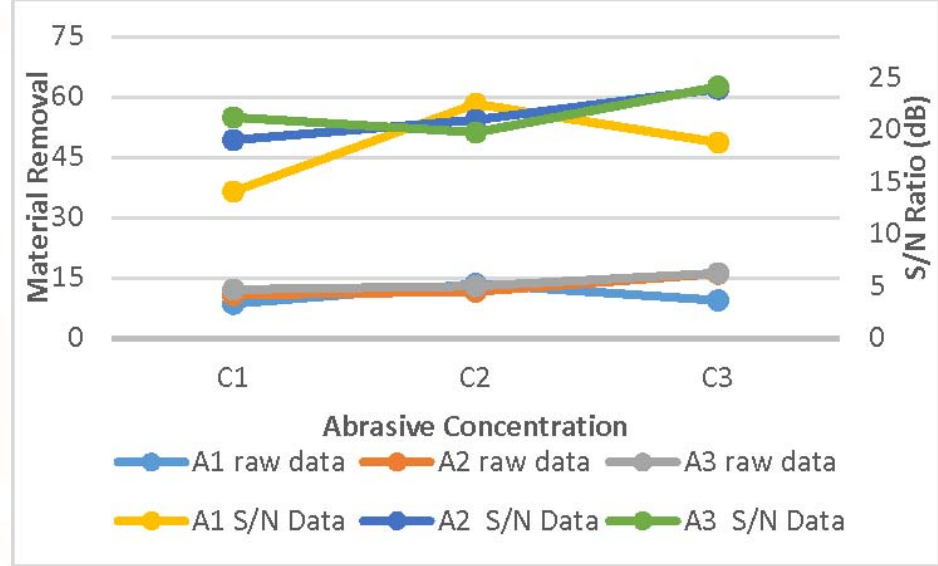




\section{ANOVA Calculation}

The analysis of variance (ANOVA) of $\mathrm{S} / \mathrm{N}$ ratio data and raw data applied to find the significant parameter and to measure their percentage contribution effect on the response characteristic. Table 4 and Table 5 indicate the pooled ANOVA results for surface roughness based on $\mathrm{S} / \mathrm{N}$ ratio data and rata, respectively. From the ANOVA, based on raw data, it is observed that all the selected parameters/parametric interactions significantly affect the material removal, except the interaction of raw data between voltage and diameters of rod (Vann). From the ANOVA based on the $\mathrm{S} / \mathrm{N}$ ratio, it is observed that all selected parameters and only one interaction of voltage and abrasive concentration (Vice) significantly affect both the mean and variation of material removal and the one interactions of voltage and salt molal concentration was not significant. According to the $\mathrm{S} / \mathrm{N}$ ratio data, salt molal concentration $(\mathrm{V}, 13.69 \%)$ has the maximum percentage contribution towards the material removal followed by abrasive concentration (C, $11.61 \%)$, voltage $(\mathrm{V}, 7.78 \%)$ and number of cycle $(\mathrm{N}, 5.02 \%)$ the interaction percentage contribution toward the material removal followed by salt molal concentration ( $\mathrm{M}, 1.21 \%)$, abrasives concentration $(\mathrm{C}, 1.17 \%)$, no. of cycle $(\mathrm{N}, 2.03 \%)$

\section{Table 4 Pooled ANOVA (Raw Data) for MR}

\begin{tabular}{|l|l|l|l|l|l|l|} 
Source & SS & DOF & V & $\begin{array}{l}\text { P- } \\
\text { value }\end{array}$ & $\begin{array}{l}\text { V- } \\
\text { Value }\end{array}$ & Critical \\
\hline V & 263.3 & 2 & 131.65 & 18.70 & 74.84 & 3.16 \\
\hline $\mathbf{M}$ & 258.63 & 2 & 129.31 & 18.37 & 73.51 & 3.16 \\
\hline $\mathbf{C}$ & 263.8 & 2 & 131.90 & 18.73 & 74.98 & 3.16 \\
\hline $\mathbf{N}$ & 137.01 & 2 & 68.50 & 9.73 & 38.94 & 3.16 \\
\hline $\mathbf{D}$ & 148.78 & 2 & 74.39 & 10.56 & 42.29 & 3.16 \\
\hline $\mathbf{V \times M}$ & 65.77 & 4 & 16.44 & 4.67 & 11.78 & 2.54 \\
\hline $\mathbf{V} \times \mathbf{C}$ & 82.897 & 4 & 20.72 & 5.89 & 12.23 & 2.54 \\
\hline $\mathbf{V \times N}$ & 86.051 & 4 & 21.51 & 6.11 & 12.23 & 2.54 \\
\hline Error & 102.03 & 58 & 1.76 & 7.25 & & \\
\hline Total & 1408.3 & 80.0 & & 100.0 & & \\
\hline
\end{tabular}

SS sum of squares, DOF degree of freedom, V variance, $\mathrm{SS}$ ' pure sum of squares, $\mathrm{P} \%$ percentage contribution of a treatment, *Significant at 95\% confidence level, Fcritical $=3.4928$.

\section{Table 5 Pooled ANOVA S/N Data}

\begin{tabular}{|c|c|c|c|c|c|c|}
\hline Source & SS & DOF & $\mathbf{V}$ & $\begin{array}{l}P- \\
\text { value }\end{array}$ & $\begin{array}{l}\text { F- } \\
\text { Value }\end{array}$ & Critical \\
\hline $\bar{V}$ & 55.86 & 2 & 27.93 & 7.78 & 1.44 & 6.94 \\
\hline $\mathbf{M}$ & 98.26 & 2 & 49.13 & 13.69 & 2.54 & 6.94 \\
\hline $\mathbf{C}$ & 83.30 & 2 & 41.65 & 11.61 & 2.15 & 6.94 \\
\hline $\mathbf{N}$ & 36.03 & 2 & 18.01 & 5.02 & 0.93 & 6.94 \\
\hline D & 26.91 & 2 & 13.46 & 3.75 & 0.70 & 6.94 \\
\hline $\mathbf{V} \times \mathbf{M}$ & 92.66 & 4 & 23.16 & 12.91 & 1.20 & 6.39 \\
\hline $\mathrm{V} \times \mathrm{C}$ & 90.34 & 4 & 22.59 & 12.59 & 1.17 & 6.39 \\
\hline $\mathbf{V} \times \mathbf{N}$ & 157.00 & 4 & 39.25 & 21.87 & 2.03 & 6.39 \\
\hline Error & 77.41 & 4 & 19.35 & 10.78 & & \\
\hline Total & 717.76 & 26 & & 100.0 & & \\
\hline
\end{tabular}

Significant at $95 \%$ confidence level, Fcritical $=19$, SS - Sum of Squares, DOF - Degree of Freedom, V Variance, SS' - Pure Sum of Squares.

\section{Conclusion}

1. The contribution of Voltage is $(48.04 \%)$ for $\mathrm{S} / \mathrm{N}$ data and $(55.28 \%)$ for raw data, Molal concentration is $(11.35 \%)$ for $\mathrm{S} / \mathrm{N}$ data and $(14.75 \%)$ for raw data, abrasive concentration is $(11.75 \%)$ for $\mathrm{S} / \mathrm{N}$ data and $(12.30 \%)$ for raw data, number of cycle is $(0.55 \%)$ for $\mathrm{S} / \mathrm{N}$ data and $(0.75 \%)$ for raw data and diameter of rod is $(1.87 \%)$ for $\mathrm{S} / \mathrm{N}$ data and $(3.0 \%)$ for raw data. The optimal parameter for percentage change in roughness was observed as V3M3C3D3N3.

2. The contribution of interaction with voltage and molal concentration $(\mathrm{V} \times \mathrm{M})$ is $(1.25 \%)$ for $\mathrm{S} / \mathrm{N}$ data and $(0.25 \%)$ for raw data, interaction with voltage and number of cycle $(\mathrm{V} \times \mathrm{N})$ is $(8.25 \%)$ for 
$\mathrm{S} / \mathrm{N}$ data and $(6.94 \%)$ for raw data, interaction with voltage and abrasive concentration $(\mathrm{V} \times \mathrm{C})$ is $(10.23 \%)$ for $\mathrm{S} / \mathrm{N}$ data and $(3.64 \%)$ for raw data.

3. Further better results can be obtained by varying parameters at different levels or by club magnetic AFM process with ECAFM or CFAAFM.

\section{Reference}

[1]. Rhoades L.J., "Abrasive flow machining with not-so-silly putty", Metal Finishing, (1987), pp.27-29.

[2]. Rhoades L.J., Abrasive flow machining, Manufacturing Engineering, (1988), pp.75-78.

[3]. Rhoades L.J., Abrasive flow machining: A case study, J. Material Processing Technology, 28, (1991), pp.107-116.

[4]. Perry W.B., Abrasive flow machining principles and practices, Non-traditional conference proceedings, (1989),IJSER pp.121-127.

[5]. Williams R.E.and Rajurkar K.P. "Stochastic modeling and analysis of Abrasive flow machining", Transaction ASME, Journal of Engineering for Industry,114,1992,74-78

[6]. Jain V.K; Adsul. S.G; "Experimental

investigations into abrasive flow machining "International Journal of Machine tool and Manufacturing,40,2002,1003-

1021

[7]. Loveless T.R,Williams R.E and Rajurkar K.P;"A study of the effects of Abrasive Flow finishing on various machined surfaces. Journal Material processing technology,47,1994,133-151.

[8]. Sing S.Shan H.S; Development of magneto abrasive flow machining process, International Journal of Machine Tool and Manufacture,42,2002,953-959

[9]. Lucjan Dabrowski; "Advancement of abrasive Flow Machining Using an Anodic Solution", Journal of New Materials for Electrochemical Systems(2006) , pp 439-445
[10]. B.S. Brar, R.S. Walia and V.P. Singh; "Electro Chemical Machining in the Aid of Abrasive Flow Machining Process", International Journal of Surface Engineering \& Materials Technology, Vol. 2 No. 1 Jan.-June 2012, pp 5-9.

[11] .R.S.Walia, H.S.Shan and P.Kumar, "Enhancing AFM process productivity through improved fixturing,"International Journal of Advanced Manufacturing Technology,vol.44,no.7-8,pp.700-

[12]. S. Singh, H. S. Shan, and P. Kumar, "Experimental studies on mechanism of material removal in abrasive flow machining process," Materials and Manufacturing Processes, vol. 23, no. 7, pp.714-718,2008.9,2009.

[13]. Gupta Ravi, M.E Thesis: Development and Investigations in Centrifugal Force Assisted Abrasive Flow Machining Process (2013), PEC University Chandigarh.

[14]. b.s. brar, r.s. walia, v.p. singh, "regression model for electro-chemical aided abrasive flow machining (eca2fm) process", 5th International \& 26th All India Manufacturing Technology, Design and Research Conference (AIMTDR 2014) IIT Guwahati, Assam, India .

[15]. Ravi Gupta, Balinder Chahal "Investigation and Optimization of Process Parameters in Electrochemical Aid Abrasive Flow Machining" International Journal of Scientific and Engineering Research Volume 6, Issue 2, February-2015 ISSN 2229-5518

[16]. B.S. Brar, R.S. Walia, V.P. Singh, "Electrochemical-aided abrasive flow machining (ECA2FM) process: a hybrid machining process",

International Journal advance manufacturing of

technology DOI 10.1007 / s00170-015-

(March 2015). 6806-yg 